\title{
CONCEPTUAL DESIGN OF INJECTION MOLD TOOL FOR THE CHAIR HAND REST COMPONENT
}

\author{
Sampath. $\mathbf{A}^{\mathbf{1}}$, Hemanth. $\mathbf{R}^{2}$ \\ ${ }^{1}$ Dept. of PG studies, Govt. Tool Room \& Training centre, Mysore, Karnataka, India-570016. \\ ${ }^{2}$ Dept. of PG studies, Govt. Tool Room \& Training centre, Mysore, Karnataka, India -570016.
}

\begin{abstract}
Plastic products are having high demand in this modern world, these plastics are processed by various methods depending upon the type of the plastic used. Here the Injection moulding is a process where molten plastic material is forced under pressure into a mould tool where it is solidified and ejected when the tool opens the two halves of the mould. This paper presents the Conceptual Design of Plastic Injection Mould Tool for Chair Hand Rest. The mould tool is of two cavity mould. The material used for the processing of the component is Polypropylene (PP). The technique is incorporated to produce a light weight with good quality component considering the ease of manufacturability, Tool design and development is a specialized and critical area. The tool design should match the machine specification and should be accurate and economical for successful life of a component or product assembly and Positive ejection of the component within the minimum possible time and cost.
\end{abstract}

Keywords: Injection moulding, Product design, Pin ejection.

\section{INTRODUCTION}

Injection moulding is one of the manufacturing processes which have a great demand in the market for the plastic products. The designer must consider the performance of the machine, process and material constraints as well. It involves a practical knowledge component about areas of customer needs. Thermoplastics have increasingly replaced conventional materials in a wide range of consumer and industrial products due to their relative strength, ease of manufacturing, and service requirements.

Most thermoplastic materials are processed the injection moulding process due to its ability to quickly form complex and precise parts. Pressure is usually maintained after the initial filling to force additional material into the cavity while the polymer melt cools and solidifies, thereby increasing dimensional stability and part performance. Once the melt has solidified, the mold opens and the part is ejected. [3][6]

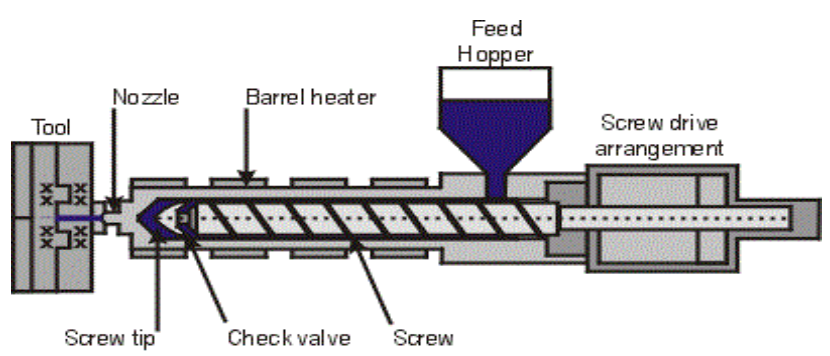

Fig- 1: Injection molding machine

\section{INJECTION MOULDING CYCLE}

The injection moulding process in which the plastic polymers are feed through hopper, from there it is sent to the barrel which is then heated with the sufficient temperature to make the plastic flow, then the molten plastic material will be injected under high pressure into the mould tool, this process is commonly known as Injection, the tool is clamped rigidly depending upon the injection pressure that will be applied to both platens of the injection moulding machine in order to hold the mould tool together. After a few seconds the product is set to cool which helps it in the solidification process. The product gets its shape the two platens will be opened for the ejection of the component this separate of the mould tool is known as mould opening and finally the moulded product is ejected or removed from the mould. And the process will repeat itself.[1]

The moulding cycle followed by closing and opening of the mould. The injection unit melts the polymer resin and injects the polymer melt into the mould. The ram fed injection moulding machine uses a hydraulically operated plunger to push the plastic through a heated region. The molten material converges at a nozzle and is injected into the mould tool. The melt is forced into the mould in two or three stages:

\section{$>\quad$ Stage 1: Fill stage}

During this stage, the molten resin fills the mould cavities. As the material is forced forward, it passes over a spreader, within the barrel, which causes heating and mixing. In this stage the Injection velocity of the plunger moves forward. 


\section{Stage 2: Pack stage}

As the molten material enters the mould, it cools and solidifies. The pack stage is necessary to force more material into the mould to compensate for solidification.

\section{$>\quad$ Stage 3: Hold stage}

When no more material can be forced into the mould, melt can still leak back through the gate. The hold stage applies forces against the material in the cavity until the gate freezes to prevent leaking of the melt.

In some machines, pack and hold are combined into a single second or holding stage. [3], [4]

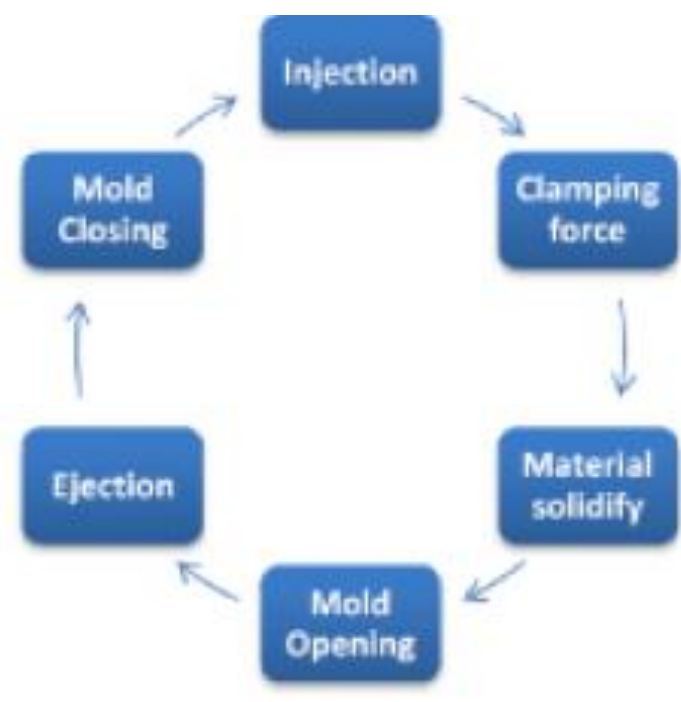

Fig- 2: Injection molding cycle

\section{METHODOLOGY}

Component is modeled using the software Solid Works. The attempt to design a mould tool which can be manufactured \& the other details of the model is shown below.

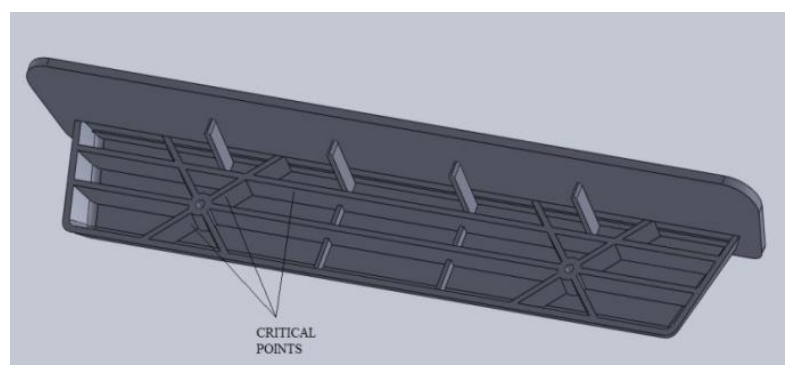

Fig- 3: Component model

For the above component (Chair Hand Rest) PP (Polypropylene) is used for the production of the component. PP is light weight $\&$ ability to be injection molded.

\section{PROPERTIES OF POLYPROPYLENE.}

\begin{tabular}{|l|l|}
\hline Component name & Chair Hand Rest \\
\hline Material & Polypropylene \\
\hline Shrinkage & $1.5 \%$. \\
\hline Density of the material & $0.9 \mathrm{~g} / \mathrm{cm}^{\wedge} 3$ \\
\hline Volume of component & $70945 \mathrm{~mm}^{\wedge} 3$ \\
\hline Weight of the component & $64 \mathrm{gms}$ \\
\hline Number of cavities & Two cavity mould \\
\hline Maximum wall thickness & $3 \mathrm{~mm}$ \\
\hline Mould type & Two cavity mould tool \\
\hline
\end{tabular}

The following are some commonly used design elements in the above shown component:

- Ribs

- Unequal wall thickness.

\section{BASIC DESIGN OF INJECTION MOLD TOOL}

Various design considerations had been applied in the design. The mould is designed based on the platen dimension of the plastic injection machine used. There is a limitation of the machine, which is the maximum area of machine platen is given by the distance between two tie bars. Therefore, the maximum width of the mould plate should not exceed this distance.

Factors to be considered during designing of injection moulding tool

$>$ Design and material of components

$>$ Number of components required

$>$ Selection of Injection moulding machine

$>$ Number of cavities

$>$ Type of tool

$>$ Selection of parting line

$>$ Positioning of core and cavity

$>$ Ejection system

$>$ Designing of layout

$>$ Fool proofing arrangements

$>$ Cooling elements

$>$ Tool life

\section{INJECTION MOULD TOOL}

The injection mould consists of three assembly units that is 1) Fixed half of the tool 2) Movable half of the tool and 3) The Ejector Assembly. And here the two plate mould is been used. The fixed half of the tool is been clamped to the machine bed where the locating ring locates the sprue to machine nozzle. And the other is been clamped to the movable side of the machine and in this the ejector assembly will be towards the same side. When the tool is closed the molten material is fed by the machine nozzle to sprue and the channels (runners and gates) are done in the tool for the material to flow into the cavities as per the requirement. (3) 


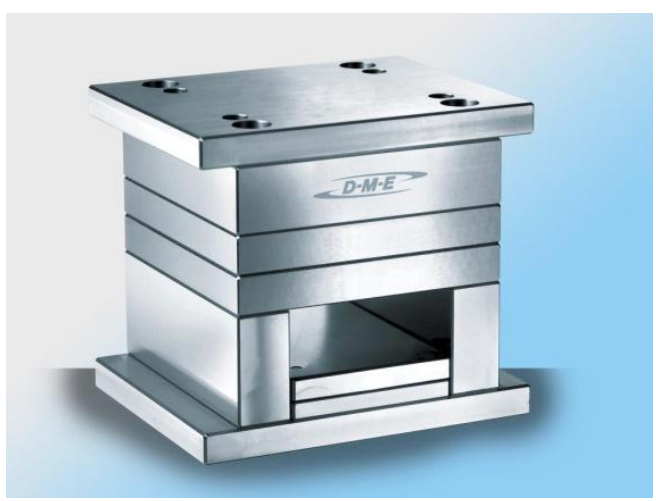

Fig-4: Two Plate Mould Tool

The two main components of the mould tool are Core and the Cavity. When the two halves of the tool is closed a parting line is generated at the parting surfaces of the tool, where the core and cavity meets and the gap between them is found for the component to be filled with the molten plastic. The mould comprises of Core, Cavity, Backing plates for core and cavity, Spacers, Feeding systems, Ejection system: ejector pins, ejector plate, ejector back plate, ejector guide bush and guide pillars, Top and bottom plate, Mould cooling items, Return pin and rest pads.(7)

\section{CORE AND CAVITY.}

Mould separate into two halves called the core and the cavity as shown in Fig $4 \& 5$ to permit the part to be extracted. In general the shape of a part must not cause it to be locked into the mould.[1][2]

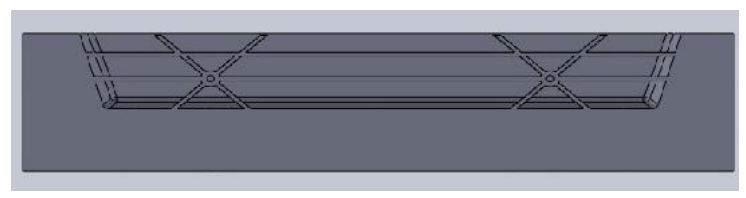

Fig-5: Core

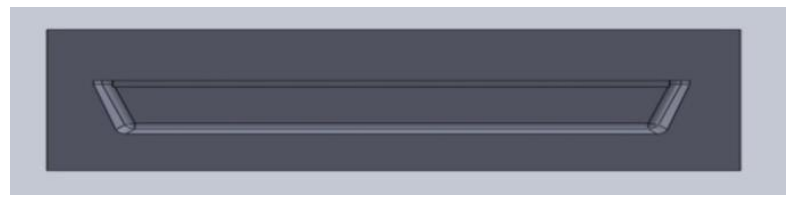

Fig- 6: Cavity

\section{EDGE GATE}

Edge gate is a general purpose gate and simplest form is merely a rectangular channel machined in one mould Plate to connect the runner to the impression and it is easy for de-gating and material savings.[3][6]

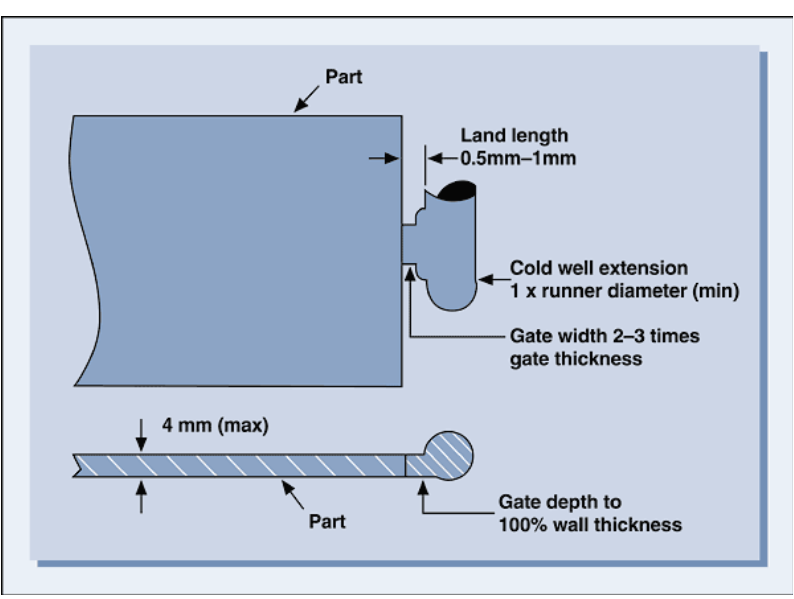

Fig- 7: Edge Gate

\section{EJECTION SYSTEM.}

An ejection system is one of the important factor in the design, here the separate consideration to be give for the ejection of the component from the mould tool. On cooling the moulded component will shrink onto and remain on the core or moving half when the mould opens.

This comprises of a:

$>$ Hydraulic actuator

$>$ Ejector plate

$>$ Ejector pins

Here Pin ejection unit will be employed for the ejection of the component. [6]

\subsection{Ejection}

Pin Ejection is the simplest method that are very effective and usually more efficiently used, wherever they can be used where there is a area possible during ejection. These moulds remove the component from the core by moving the solidified component which sticks to the core. Typical applications are longer, square or rectangular boxes.

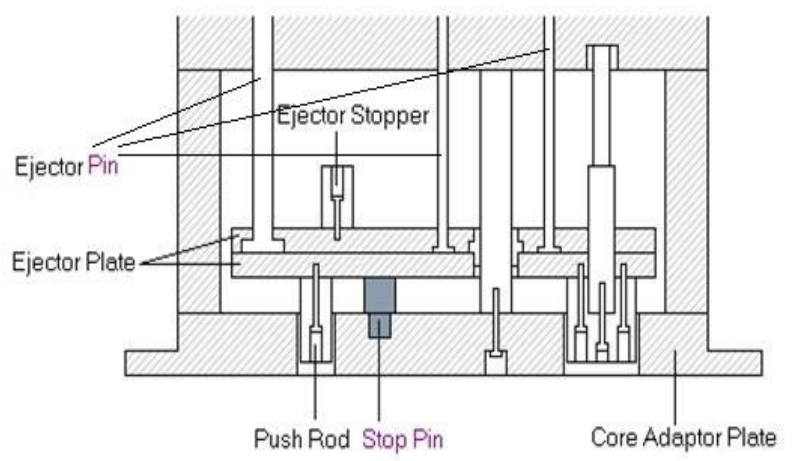

Fig- 8: Pin Ejection 


\section{CONCLUSIONS}

The work, deals with the Conceptual design of injection mould tool for Chair Hand Rest. The Two Plate mould design and Pin ejection will make it possible to produce high quality product at minimum cost. The End product will be produced with less number of defects with good quality and good finish.

\section{REFERENCES}

[1]. S.H.Tang, Y.M.Kong, S.M.Sapuan, "Design and thermal analysis of Plastic Injection Mold Tool." Sep-2004

[2]. Lyudmila Dulebove, "Optimization of Injection Moulding Manufacturing For automotive Injection” 2012

[3]. Injection Mould Design, R.G.W. Pye.

[4]. Technical Directory on Design and Tooling for Plastics, CIPET.

[5]. The Mould Design Guide by Peter Zones.

[6]. Injection Mould Design, Rapra.

[7]. "Materials for Injection Moulding", Branislar Dublea, Frantisek - 2012. 